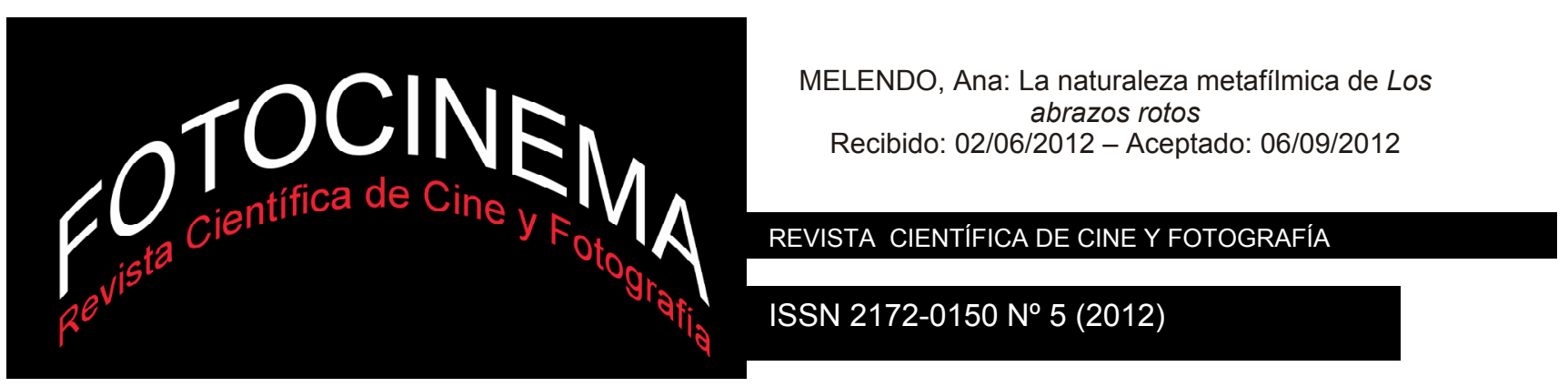

\title{
LA NATURALEZA METAFÍLMICA DE LOS ABRAZOS ROTOS
}

\section{METAFILMIC NATURE OF BROKEN EMBRACES}

\author{
Ana Melendo \\ Universidad de Córdoba
}

\section{Resumen:}

El artículo profundiza en las señas escriturales marcadas por la autorreferencialidad y la autorreflexión diseñadas a partir, entre otras cuestiones, de la recurrencia al uso de material cinematográfico como fuente de inspiración que se dan cita en Los abrazos rotos; y cómo Almodóvar encuentra un método eficaz en el metacine para meditar y teorizar sobre la imagen y su evolución activando con esa finalidad los mecanismos necesarios que le permiten bucear en un territorio afín que se viene denominando poscine, un territorio en el que el artista demuestra, una vez más, su innegable amor hacia el arte y la imagen cinematográfica, reaccionando ante esa pulsión metaficcional que lleva al cine a volverse sobre sí mismo para pensar sobre sus propios medios expresivos.

\begin{abstract}
:
This article analyzes the narrative elements in Broken Embraces marked by self-referentiality and self-reflection arising from, among other things, the usage of cinematographic material as a source of inspiration. It examines how Almodóvar encounters an effective method in metafilm to meditate and theorize on the image and its evolution. The filmmaker activates the necessary mechanisms in order to explore a related territory that has come to be called postcinema. Once again, the artist shows his undeniable love for art and the cinematic image. Almodóvar reacts to the metafictional impulse that permits cinema to reflect upon itself and its own means of expression.
\end{abstract}

\section{Palabras clave:}

Metacine; poscine; metaficcional; autorreferencialidad; autorreflexión.

Key words:

Metafilm; post-cinema; metafictional; self-referentiality; self-reflection. 
En la década de los años veinte del pasado siglo, surge una serie de artistas procedentes de distintas disciplinas interesados por trasladar al cine muchos de los planteamientos que se venían desarrollando en las vanguardias artísticas, y también para algunos de ellos, el cine supone el motor de arranque de determinados conceptos que se trasladarán a otras artes como la pintura. Pero desde el punto de vista que aquí nos ocupa, lo más interesante de la producción fílmica de artistas como Man Ray, René Clair, Fernad Leger o el mismo Buñuel, es que se cuestionan de una manera radical el lenguaje cinematográfico. Efectivamente, en contra de lo que promulga el cine clásico de Hollywood o cine de la transparencia, existe otra corriente de cineastas que lejos de pasar desapercibida o de borrar todo rastro de estilo en favor de la historia que la película pone en pie, se preocupan por manifestar la subjetividad del creador y una autoconciencia lingüística que alcanza su máximo esplendor en la década de los años cincuenta con movimientos como la modernidad cinematográfica, la Nouvelle Vague o los Nuevos cines, de tal manera que la transparencia narrativa se ve mermada al primarse la forma sobre el contenido, por lo que comienzan a proliferar los estilemas y los rasgos de la personalidad creativa de dichos autores. Es ahora, después de que el cine haya afianzado sus propios medios de expresión, influido en muchos casos por las teorías escénicas de Bertolt Brecht, cuando este medio de expresión siente la necesidad de interrogarse sobre sí mismo y sobre las actitudes narrativas que se habían venido manifestando hasta entonces en él. Pedro Almodóvar, en línea con esta tradición de cineastas que surge a mitad del siglo XX, promueve en su cine unas señas escriturales marcadas por la autorreferencialidad y la autorreflexión diseñadas a partir, entre otras cuestiones, de la recurrencia al uso, al igual que sus colegas franceses, de material cinematográfico como fuente de inspiración (Marku, 2001:118). Pero además y sobre todo, el artista manchego encuentra un método eficaz en el metacine para reflexionar y teorizar sobre la imagen, y su evolución, una reflexión que da un paso más, como veremos, con respecto a estos 
representantes de la modernidad, porque, como dice Ángel Quintana:

"Es como si la modernidad cinematográfica se encontrara ante unos caminos propios que la llevaran a reflexionar sobre la imagen al margen del arte, como si las investigaciones de los videoartistas que empezaron a surgir en el territorio de la cultura visual no le interesaran excesivamente al no formar parte de su mundo" (Quintana, 2011: 133).

Pues bien, a Almodóvar sí le interesa, y mucho. Por eso, activa los mecanismos necesarios para bucear en ese territorio afín que finalmente se ha denominado poscine, un territorio en el que el artista demuestra una vez más su innegable amor hacia el arte y la imagen cinematográfica reaccionando ante esa pulsión metaficcional ${ }^{1}$ que lleva al cine a volverse sobre sí mismo y a reflexionar sobre sus propios medios expresivos. El mismo artista declara al respecto:

"En mis películas el cine está presente, pero no soy un cinéfilo, no soy una persona que cita a otros autores [...] Cuando una película sale en una película mía no es un homenaje, es un robo. Lo robo y hago que forme parte de la historia que he escrito, por eso funciona de un modo activo, mientras que un homenaje siempre responde a una cosa pasiva [...] Convierto el cine que he visto en mi propia película, y por lo tanto en la de los personajes (Strauss, 1995: 65)".

Es nuestro propósito en este artículo, a partir del análisis textual de Los abrazos rotos, indagar sobre la naturaleza metafílmica que plantea el penúltimo film del cineasta manchego, hasta el momento, para detectar las estrategias metaficcionales, reflexivas y e intertextuales que el mismo pone en juego. Y más allá de eso, establecer las formas de hacer del film en relación a las mismas, profundizando en las relaciones que estas prácticas formales sostienen con el plano del contenido. Para ello partimos de la clasificación establecida por José Antonio Pérez Bowie en relación a la descripción del fenómeno y las peculiaridades que puede revestir dicho tratamiento en la pantalla, pues consideramos que en Los abrazos rotos se dan cita todas ellas. Es decir, que la película de Almodóvar, en la terminología utilizada por Pérez Bowie, responde al contenido originario del término metaficción o el cine dentro del cine; propone una reflexión sobre

${ }^{1}$ Entiéndase metaficción como la ficción en segundo grado o ficción dentro de la ficción. 
sus propios medios expresivos transgrediendo las convenciones de la narración clásica a través de una instancia enunciadora; y el cine aparece como intertexto en sus múltiples variantes según la noción genettiana de

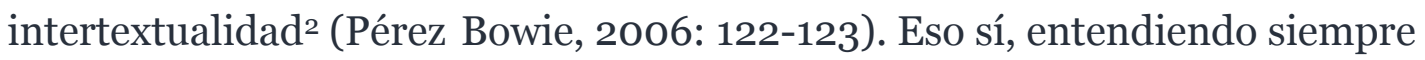
que los géneros cinematográficos, como dice Mark Allinson, y Pedro Poyato subraya posteriormente, en el cine del artista manchego, “adquieren, al estar recontextualizados, nuevos significados" (Allinson, 2003: 282); “esos fragmentos de otros textos, como si de una operación de trasplante se tratara, empiezan a latir al ritmo marcado por el nuevo cuerpo textual donde son implantados, adquiriendo por ellos una nueva dimensión, un nuevo sentido" (Poyato, 1999: 97-98). En esta lógica, anota Jean-Max Méjean que “todas estas referencias, si bien no son exhaustivas, intentan demostrar la voluntad de un Pedro Almodóvar perfectamente consciente de que no basta con adorar el cine, sino que también hay que perpetuarlo (Méjean, 2007: 32). Esta idea cobra un particular interés en Los abrazos rotos puesto que, a través de los mecanismos que el film incorpora, se establece un estudio muy interesante sobre el nuevo futuro de la imagen cinematográfica amparada en la imagen tecnológica y su integración en la nueva cultura informática durante todas las fases del desarrollo del film. Pero veámoslo en lo que sigue.

\section{Los abrazos rotos: el cine más allá del cine}

El protagonista de Los abrazos rotos es un cineasta que, al igual que Almodóvar, crea relatos a partir de otros relatos. No es la primera vez en la filmografía de este autor que aparece la figura del director de cine como un síntoma, sin duda, de carácter autorreferencial; pensemos en títulos como Laberinto de pasiones (1982) y iÁtame! (1990), entre otros. De tal manera que, como dice Daniela Aronica, "la autorreferencialidad se convierte así en una herramienta para insinuarse hasta los más recónditos pliegues de su universo existencial sin tenerse que desnudar ante el espectador de forma explícita” (Aronica, 2005: 78). En este caso, se trata de un cineasta que,

2 Véase al respecto: (Genette, 1989). 
paradójicamente, queda ciego tras un accidente de coche sufrido en Lanzarote en el que la mujer que ama pierde la vida, con lo cual, los ojos, mecánicos o no, que aparecen en la película, adquieren una pregnancia especial.

El film comienza con un prólogo en el que se invita al espectador a que se identifique con el ojo artificial de una cámara de vídeo de control que, conectada a una de las Panavision ${ }^{3}$ con las que se lleva a cabo parte de la película, permite ver las tomas durante e inmediatamente después de rodarlas sin que estas sean impresas [foto 1]. Precisamente, las

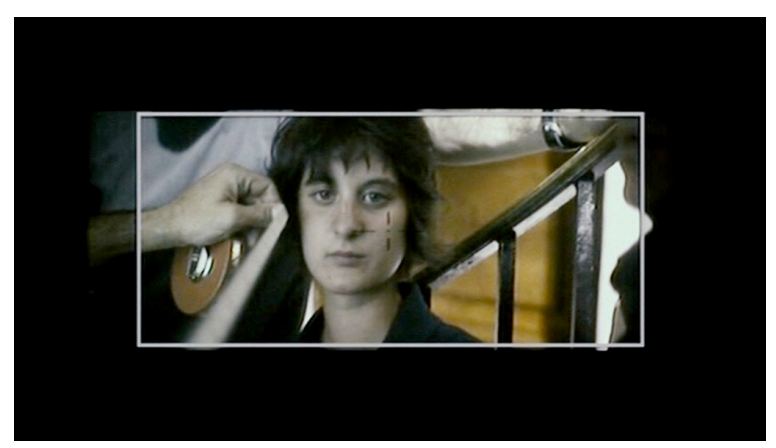
características particulares de dicha cámara hacen posible la diferenciación textural entre este grupo de imágenes y las que aparecen después del segundo fundido a negro que tiene lugar en el film.

El primero de ellos, ese en el que se impresiona el título de la película, provocado por uno de los miembros del equipo al interponerse entre la cámara y los personajes que se encuentran detrás de la misma -después de que el director de fotografía de la película haya ensayado posiciones con ellos-, adquiere un protagonismo esencial porque propone una representación en abismo - “el cuadro dentro del cuadro” que diría Julián Gállego para referirse a un procedimiento recurrente en la pintura barroca (Gállego, 1987)-, que anticipa el interés que muestra la película por presentar al cine como un contenedor que puede albergar en su interior distintas representaciones cinematográficas dispuestas a modo de matrioskas que se relacionan entre sí, estableciendo lazos de continuidad entre la realidad y la ficción, unos lazos que, si bien parecen rotos por la

\footnotetext{
3 Es un detalle a tener en cuenta para el desarrollo de este artículo que la película fue rodada con una Panavision Millennium como cámara A, la Arriflex 435, la Arriflex 416, y la Panavision Platinum, que además de funcionar como segunda unidad, aparece en la película como atrezzo cuando el protagonista, que es director de cine, rueda Chicas y maletas. En digital, la Panavision Genesis captó unas imágenes de la cena en un restaurante donde los protagonistas estaban en total oscuridad, aunque no llegó a la versión final de la película.
} 
intromisión del título del film en un momento determinado de este prólogo, la textura de la imagen - que continúa siendo la misma- y la aparición de Penélope Cruz y Lluís Homar en la pantalla sustituyendo a los miembros del equipo y ocupando posiciones para interpretar una de las escenas que tendrá

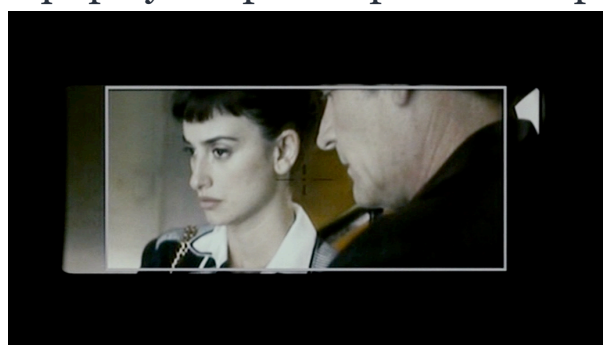

lugar posteriormente en este largometraje, confirman la fusión entre realidad y ficción en la película de Almodóvar [foto 2]. El propio cineasta declara al respecto:

"Elegí estas imágenes para empezar la película porque son imágenes usurpadas y furtivas que ya establecen el cine como territorio donde transcurrirá gran parte de la acción. También porque me fascinan las escena casuales que cruzan por delante de la cámara en los momentos que no se está rodando" (Almodóvar, 2009: 7).

Almodóvar reivindica así la ruptura del espacio fílmico tradicional, de manera que el elemento fundamental de la imagen pasa a ser la superficie y constitución de la misma. Ángel Quintana anota para referirse a este proceso que tiene lugar en el cine cómo:

“A partir del momento en que el artista ha manipulado el mundo mediante los instrumentos propios del arte cinematográfico -la tecnología de la puesta en escena y la tecnología del montaje- la mímesis deja de tener la apariencia de analogía respecto al mundo originario para transformarse en el elemento determinante de la puesta en serie" (Quintana, 2003: 61).

En todo caso, tras ese fundido a negro, el espectador se ve sumergido de lleno en la ficción a través de un primerísimo primer plano, cuya textura ya ha variado con respecto a los anteriores. Efectivamente, la Panavision da cuenta de un ojo femenino que ocupa todo el plano. A modo de telón, el párpado y las largas pestañas bañadas en rímel del mismo dejan al descubierto un iris de color verde que, como si de un espejo se tratara, muestra aquello que queda fuera de campo: la imagen de Harry Caine, según la voz del propio protagonista del film, y las páginas de un periódico que vinculadas al rostro de él, mediante el reflejo de las mismas en el ojo de la chica, lo devuelven al 
pasado, un pasado del que la película da cuenta en estos primeros instantes a través de la voz de un narrador autodiegético ${ }^{4}$, el propio Harry Caine [foto 3].
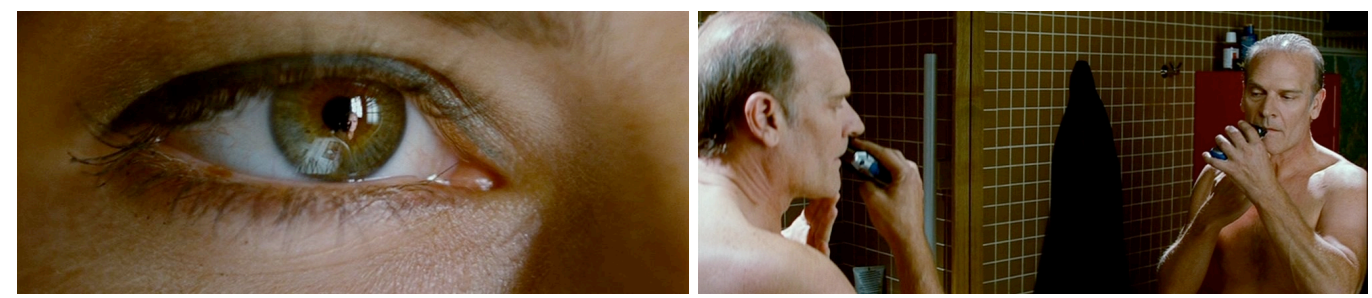

La voz de Caine, pone de manifiesto en este inicio una de las señas de identidad del film: la figura del doble, que queda inmortalizada a través del espejo a la vez que la voz over explica cómo Mateo Blanco, director de cine, pasa a ser de manera abrupta Harry Caine, escritor. Es así cómo el doble se consolida desde el comienzo, a partir del encuentro de Mateo Blanco, el sujeto principal, con su otro “yo”, Harry Caine. El espejo se convierte así en el lugar que mediante el reflejo duplica la realidad convirtiéndola en otra cosa [foto 4]. Francisco Perales anota al respecto que:

"La doble identidad y la suplantación física es una de sus fijaciones [refiriéndose a Almodóvar] permanentes. A través del espejo (The Dark Mirror, 1946, Robert Siodmak), Su propia víctima (Dead Ringer, 1964, Paul Henreid) y Tú a Boston y yo a California (The Parent Trap, 1961, David Swift), son referentes a los que suele recurrir" (Perales, 2008: 191).

A tal efecto, explica Almodóvar:

"Como para muchos autores la ficción fue un ensayo de la realidad. Un director que no puede dirigir, que además ha perdido a la mujer que adora, solo tiene ante sí dolor y desesperación; si quiere sobrevivir tendrá que hacerlo a través de la impostura" (Almodovar, 2009: 11).

A partir de este momento, y precisamente partiendo de la imagen especular, la película de Almodóvar se puebla de imágenes que profundizan en el misterio de la percepción más allá de la apariencia, bien sean fotográficas, digitales, o incluso radiográficas; sin obviar, por su puesto, aquellas que dan cuenta de algunos de los textos artísticos más queridos por el cineasta español como: la pintura explícita de Warhol o la de Magritte a través del

4 Término utilizado por Genette para referirse a aquél que narra los acontecimientos de la historia y que puede ser un personaje testigo de lo que ocurre o puede ser protagonista de lo que está contando. 
tableau vivant protagonizado por Lena y su amante; carteles de películas como el de La noche, de Antonioni; y fotografías de actrices fetiches del cineasta manchego como Bette Davis o Romy Schneider, quien aparece en un fotograma extraído de la película Lo importante es amar (Zulawski, 1975), e implícitamente en las palabras que configuran el cuadro que cuelga sobre el cabecero de la cama de Lena: "Je t’aime”.

Pero, en este juego de intertextos al que Almodóvar nos tiene acostumbrados, nos interesa destacar tres títulos que cobran una importancia fundamental en el film en relación al estudio de la imagen y la naturaleza metaficcional y autorreflexiva que este pone de manifiesto. Nos estamos refiriendo a: $E l$ fotógrafo del pánico (1960) de Michael Powell, Blow up (1966) de Michelangelo Antonioni y Persona (1966) de Ingmar Bergman.

Si hemos de hallar un nexo de unión entre El fotógrafo del pánico, Blow up, Persona y Los abrazos rotos, diríamos que se encuentra en un intento por parte de los cuatro films, por cifrar el mito de la creación fo-cinematográfica como posibilidad constitutiva del mundo, constructora de una realidad que desemboca en un alto nivel de verdad, así trataremos de mostrarlo en lo que sigue.

\section{1. Restitución de una verdad a través de la imagen fo-cinema- tográfica5 en Blow up, Persona y Los abrazos rotos}

Nos sumamos a la teoría de Ángel Quintana en la que explica que la imagen nodal creada por Almodóvar, aquella en la que los amantes se funden en un beso, reúne en ella a esa otra fundacional del cine moderno, los amantes calcinados de Viaggio in Italia (Rossellini, 1954) por un lado, y por otro, a la última ampliación de la fotografía protagonista en Blow-up (Quintana, 2009: 28). Pero recordemos, que sobre esa imagen nodal a la que se refiere Quintana, o mejor dicho, acariciándola, aparecen las manos de Mateo Blanco

\footnotetext{
5 Con el término "fo-cinema-tográfica", tratamos de sincretizar la doble vertiente de la imagen fotográfica y cinematográfica; imágenes patentemente vinculadas en relación a su naturaleza, pero a la vez diferentes en lo que respecta a sus posibilidades estética y de significación (Poyato, 2006: 5).
} 
recorriendo la pantalla en la que se muestra este instante sustraído al tiempo; de manera que, aunque solo sea por la vinculación iconográfica, hemos de añadir a este trío intertextual un cuarto título, Persona, cuya presencia implícita veremos que no es tan simple como podría parecer. Nos gustaría, por tanto, profundizar en cómo Blow up, Persona y Los abrazos rotos disponen redes de ida y vuelta con fines comunes desde el origen mismo de su creación.

En relación a los lazos que Los abrazos rotos establece con Blow up, hemos de comenzar recordando que el protagonista de la película de Almodóvar se desdobla en dos pasiones: la literatura y el cine, y en cada caso adopta un nombre diferente: Harry Caine y Mateo Blanco respectivamente. En este sentido, hemos de explicar que el germen de Blow up se halla en un cuento de Cortázar: Las babas del diablo (1959), cuyo protagonista, Michel, es un escritor y fotógrafo a la vez, que adquiere una conducta aparentemente esquizofrénica con trastorno de personalidad múltiple, que hace patente la ambigüedad desde el comienzo del relato, con lo cual, Almodóvar vincula el suyo a la matriz misma del origen de Blow up. Así, el cineasta manchego cuenta, cómo la raíz, a nivel visual, de su película se haya en una foto que hizo en Lanzarote en un momento de profunda oscuridad para él (Heredero, 2009: 9), de forma que la conexión entre el hipotexto en el que se basa el film antonioniano y el texto de Almodóvar, encuentran justificación, igualmente, desde el momento en que Cortázar, partiendo de una fotografía realizada por su amigo Larraín en la Isla de Saint Louis, inventa un alter ego, mitad Cortázar y mitad Larraín, es decir, mitad escritor y mitad fotógrafo, con la intención de dinamitar los mecanismos de la ficción y el discurso narrativo.

De más está señalar que ese cuento es transduccido, según la terminología utilizada por Darío Villanueva (Villanueva, 2008: 54), pertinentemente por Antonioni y su guionista inseparable, Tonino Guerra ¿̇Será casualidad que el nombre de este último figure inserto en la ficción almodovariana? Desde luego que no. El hecho de que Judit, una de las protagonistas del film, demande a su hijo el libro de Tonino Guerra, incluyéndolo en su maleta antes de salir a buscar localizaciones, solo es una argucia más de Almodóvar para 
mostrarnos algunos de los caminos reescriturales que ha recorrido hasta construir su relato, un relato en el que por cierto, aunque la historia cobra un protagonismo esencial, no desdeña la posibilidad de investigar sobre el poder y el misterio de la imagen y la dualidad inseparable que entraña; esa que, igualmente, se constituye en uno de los puntos nucleares del film antonioniano: la diferencia entre ver y percibir.

Llegados a este punto cabe señalar cómo la película de Almodóvar se puebla de imágenes fotográficas, insistiendo una vez más, como dice Nuria Vidal, en la importancia que adquiere este medio de expresión en todas las películas del autor, jugando un papel decisivo en la narración e interviniendo directamente en el relato (Vidal, 1998: 340). Pero de entre todas las fotografías que Mateo realiza con su cámara en esa especie de luna de miel

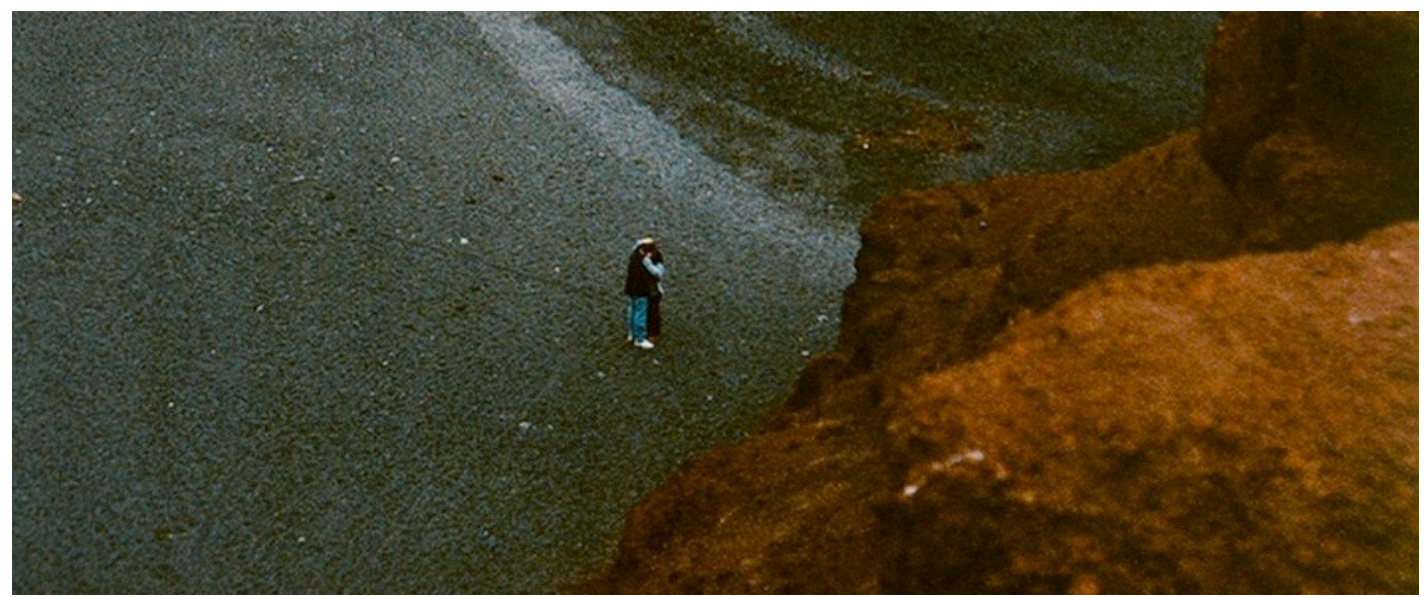

que llevan a cabo los protagonistas en la Isla de Lanzarote, destaca una a la que el protagonista denomina "El secreto de la playa del Golfo" [foto 5], porque hasta que no procede al revelado, no percibe que en ella aparece una pareja a la que no vio en el momento de realizar la fotografía, precisamente

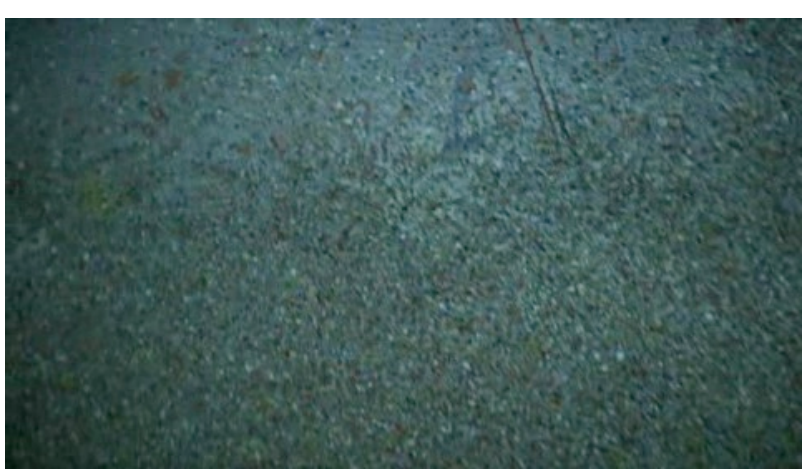
en la Playa del Golfo, según las palabras del propio Mateo que expresa lo siguiente al respecto: "Cuando hice la foto no vi a la pareja besándose”. Y sin embargo, se trata de un secreto que tiene que escribir 
para, según él, averiguar cuál es. Es pues, sin lugar a dudas, una fotografía que claramente remite a Blow up, pero no solo porque los protagonistas de ambos film hacen visible a través de este medio de representación la forma no visible, sino porque la pareja fotografiada parece inscribirse en uno de esos cuadros de Bill, el personaje pintor de la película de Antonioni [foto 6, precisamente cuando dicha fotografía comienza a dar cuenta de su materialidad misma; o incluso, en una de Las montañas encantadas ${ }^{6}$ de Antonioni.

En todo caso, ese abrazo de la pareja fotografiado por Mateo en la Playa del Golfo, solo marca el inicio de otros muchos protagonizados por Lena y él en lo sucesivo del film que quedan inmortalizados, como certificado de su existencia, en los numerosos fragmentos que, años después, el hijo de Mateo intenta reconstruir.

No obstante, en uno de los gestos más bellos del cine almodovariano la imagen de otro beso es congelada y ampliada hasta alcanzar sus cotas más altas de expresión, a través, precisamente, de mostrar su materialidad [foto 7]. Según Almodóvar:

"En esta imagen, puede ser un defecto que se vea el pixelado, pero esto es lo bueno de la tecnología digital, que si la conoces a fondo puedes encontrar muchas cosas que no son las convencionales, pero sí son dramáticamente interesantísimas, y ese es un camino que tenemos que recorrer y que yo quiero recorrer" (Heredero, 2009: 11).

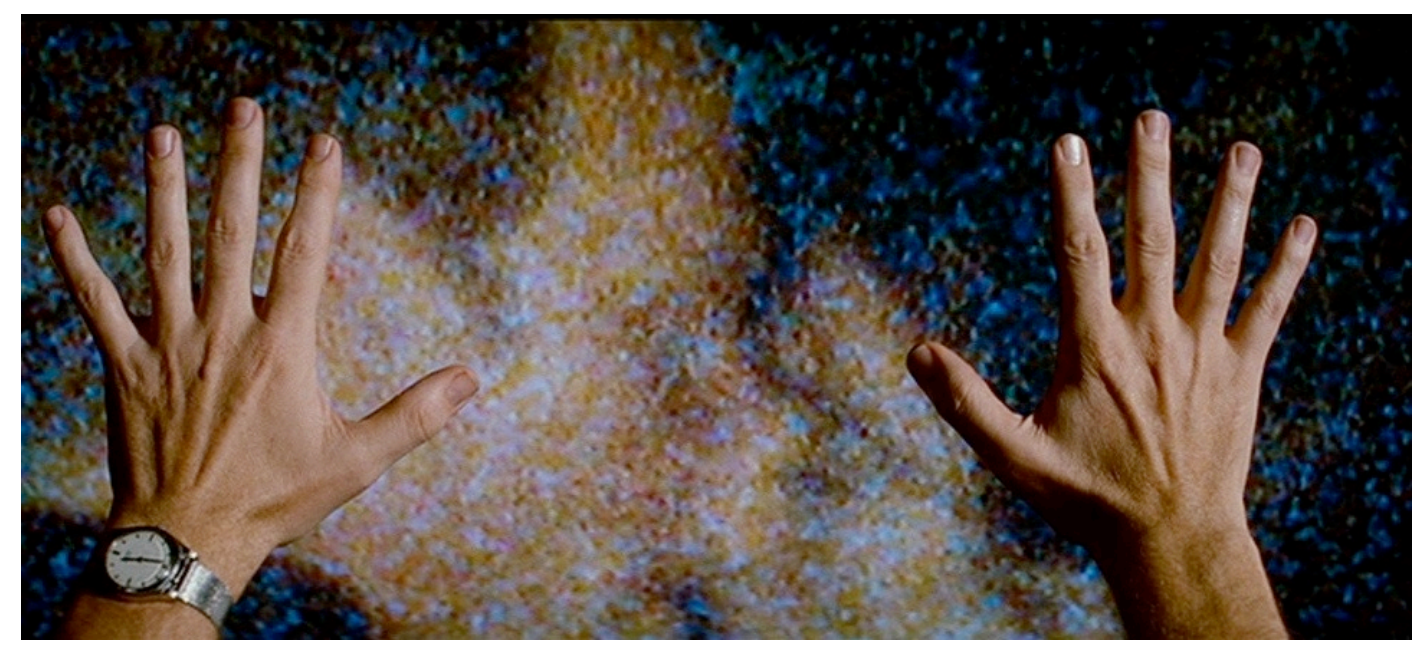

${ }^{6}$ Serie pictórica en la que el cineasta ferrarés fotografía la obra original para luego fotografiarla, dejando así al descubierto las texturas que surgen de la misma. 
Lejos de incurrir en un defecto la imagen apenas perceptible de Mateo y Lena besándose, similar a la última de la serie del fotógrafo de Blow up [foto 8], esa que Mateo no puede ver, se convierte en la imagen reveladora a través del gesto del protagonista que desliza sus manos sobre la superficie emborronada y saturada de texturas que, tras apretar el play, adquiere de nuevo temporalidad. Ambos cineastas, Antonioni y Almodóvar, dotan de sentido a esa pérdida de la forma reconocible, cuando, en palabras de Fontcuberta, "se alcanza el grado cero de la inscripción visual, que permite indagar en la composición íntima de las imágenes" (Fontcuberta, 2010: 46), por mucho que la estructura interna de la imagen almodovariana esté constituida a partir de pixeles y de que, como afirma Quintana, el molde original que preservaba la huella del mundo físico se halle difuminado; aún así esta imagen digital continúa capturando la huella de la realidad empírica (Quintana, 2011: 72).

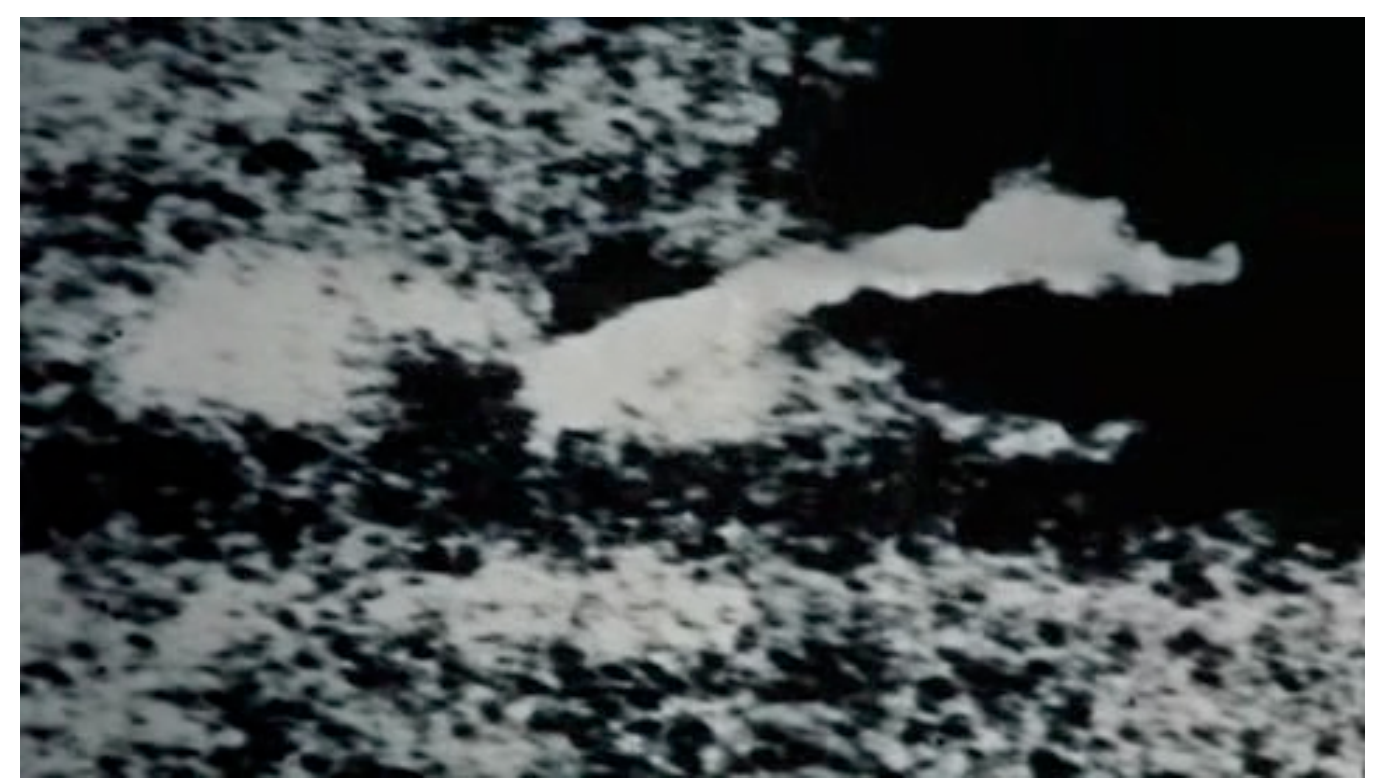

Es así cómo, apoyándose en el dramatismo que supone este gesto de Mateo, mostrando en una imagen las manos de él acariciando otra imagen, el cineasta manchego descubre que detrás de una imagen no hay ningún misterio, sino otra imagen. El protagonista construye así una imagen mental de aquello que su ceguera se empeña en ocultar; una imagen que supone su 
pasarela personal entre la realidad y el mundo al que desearía regresar, una pasarela que aparece igualmente en el comienzo de Persona como veremos.

Y es que, después de que Bergman destruye, tal y como anota Juan Miguel Company, "la fascinación del efecto de realidad, base de la representación cinematográfica dominante, mostrando toda la cacharrería distanciadora que encuentra a mano, toda la tramoya del dispositivo" (Company, 1981: 85) al que, aunque de forma distinta, también Almodóvar somete el inicio de Los abrazos rotos, un adolescente abandona su posición fetal buscando la mirada del Otro materno, aquella que lo sostiene y que lo certifica en la formación del yo (Lacan, 1984: 211-212), una mirada que este chico encuentra en la

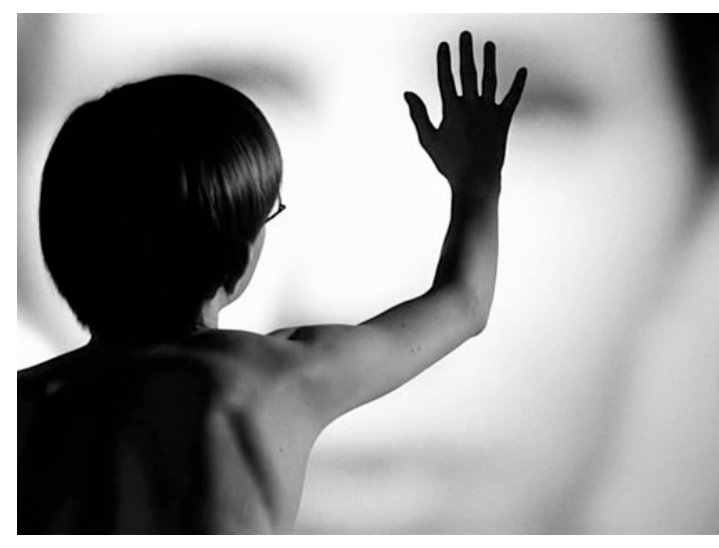
imagen borrosa y fluctuante de un retrato sobre el que pasa la mano, formado por la conjunción de dos: Alma y Elisabeth, una conjunción, que en la película de Bergman pone de manifiesto, a igual que en Los abrazos rotos, la dualidad del yo (foto 9). En este sentido, se produce en la segunda parte de Persona, la simbiosis entre estas dos mujeres, "una fusión simbólica” en palabras de Company (Company, 1981: 93), una fusión que se va trabajando a lo largo de todo el film a través de los distintos modelos de imagen que van apareciendo; nos referimos fundamentalmente a la imagen especular y la imagen fotográfica.

La imagen especular se muestra en el film como identificadora del sujeto, de Alma en este caso, que la confronta con ella misma y al mismo tiempo supone una experiencia de división, recordemos que Alma confiesa a Elisabeth que quisiera ser como ella. Lo mismo que el fotograma nuclear del film, aquel que bajo la pérdida de la forma real, mediante un primerísimo primer plano termina por unir los rostros de ambas protagonistas y los escinde a la vez convirtiéndolos en materia moldeable que encuentra su continuidad en la última imagen del relato, esa en la que el niño del comienzo sigue acariciando la imagen borrosa, de contornos desdibujados, 
configuradora, según expone Lacan en su teoría del estadio del espejo, de la imago corporal del chico, una imagen que no hace sino certificar, al igual que el fotograma acariciado por Mateo Blanco, la pura materialidad de una película que insiste en la componente constitutiva del film, y que ofrece al espectador distintos mecanismos de reflexión en relación a la imagen, incluida la televisiva o electrónica y su carácter de inmediatez, algo que también podemos observar en el film almodovariano que nos ocupa. Y es que, tanto Bergman como Almodóvar, parecen estar de acuerdo en la observación realizada por el cineasta sueco en la que afirma que:

"Literatura, pintura, música, cine y teatro se procrean y se dan a luz a sí mismos. Surgen y se aniquilan nuevas mutaciones, nuevas combinaciones, el movimiento visto desde fuera parece nerviosamente vital -no es más que el extraordinario afán de los artistas por proyectar, para sí mismos y para un público cada vez más distraído, la imagen de un mundo que ya no se preocupa de sus gustos o sus ideas" (Bergman, 1992: 47).

\section{2. Ray X y su cámara de vídeo}

Dice Ángel Quintana en relación a la imagen electrónica:

“La imagen electrónica transformó la huella del referente en electrones móviles susceptibles de ser transportados de un sitio a otro [...] El vídeo posibilitó que se pudiera conservar la emisión y volver a verla, traicionando de este modo la esencia del medio, pero confiriendo a la imagen un estatuto más privilegiado como producto, como archivo o como creación susceptible de ser considerada obra por su valores artísticos" (Quintana, 2011: 58,63).

Almodóvar, en su periplo por el estudio de la imagen en Los abrazos rotos, no quiere pasar por alto las posibilidades de la imagen electrónica e introduce la figura del marking of, que encarna en el personaje de Ray X. En estos momentos, estaríamos en situación de comparar la película almodovariana con otra de las fuentes de la que, sin lugar a dudas bebe, nos estamos refiriendo a El fotógrafo del pánico. Aunque es cierto que en numerosas ocasiones Los abrazos rotos remiten al film de Powell en multitud de detalles - recordemos el primerísimo primer plano de un párpado que se abre dejando al descubierto el iris asustado y azul que 
permanecía oculto [foto 10] y que podemos asemejar a ese otro diseñado por Almodóvar [ver foto 3]; en el gesto del protagonista midiendo con una cinta métrica el rostro de su próxima víctima, semejante a otro que se da en el comienzo de Los abrazos rotos; o en la propia ceguera, presente también en

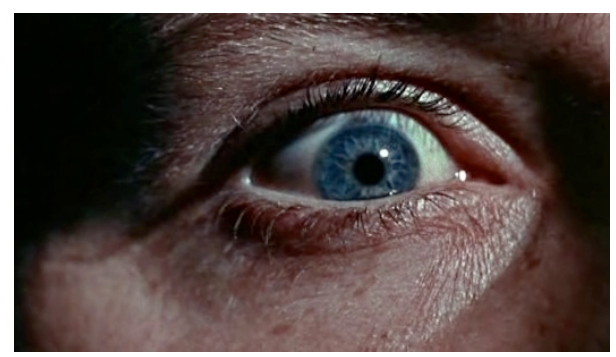

El fotógrafo del pánico; y un largo etcétera-, lo verdaderamente interesante de ambos films es cómo uno y otro abandonan la intriga de lo que podría haber sido un thriller, convirtiendo la trama en una excusa para centrarse en el proceso creativo del cine. El mismo Almodóvar declara al respecto que: "Los abrazos rotos es un drama con tintes muy negros, lo más parecido a un thriller de los años 50" (Almodóvar, 2009: 10).

Para ello, el cineasta manchego no duda en crear un personaje mediante el cual establece una narración paralela a la original: Ernesto "hijo", alias: Ray $\mathrm{X}$. A través de este personaje, Almodóvar insiste en resquebrajar los límites entre unos textos y otros, de tal forma que, nuevamente, se vale de la duplicidad que impera en todo el film, extrapolando así a Mark, el protagonista de El fotógrafo del pánico, para convertirlo, a su modo, en Ray $\mathrm{X}$. Es un trauma infantil lo que impulsa a Mark Lewis a cometer todos los asesinatos que son visualizados a través de su $16 \mathrm{~mm}$ de la que nunca se separa. Una relación tortuosa con su padre que, igualmente, vemos reflejada en el binomio Ernesto "padre" y Ernesto "hijo", una relación a la que el joven solo encuentra salida a través de su cámara de video, que como Mark, siempre lleva consigo, con el fin, en los dos casos, de realizar un documental, un documental que convierta a la imagen en la prueba absoluta de lo real, en imagen reveladora.

Y para que no quepa duda de que Mark, o mejor dicho, la cámara de este, encarna en Ray X, y teniendo en cuenta que nada es casual en el cine de Almodóvar, el origen de la creación de dicho personaje, se encuentra justo allí donde acaba Mark, dotándolo así de una continuidad absoluta. La voz over de Mark, ya muerto por cierto, lee aquello que el último plano del film 
muestra en imágenes: un cuaderno en el que aparece escrito: “iUna cámara mágica que necesitará la ayuda de otro! X” [foto 11], y ese otro, es convertido por Almodóvar en Ray X. Y es que tal y como indica Francisco Perales, "Pedro Almodóvar utiliza una situación o personaje como elemento de arranque argumental y lo ubica en un nuevo contexto donde se relacionará con otros individuos" (Perales, 2008: 288).

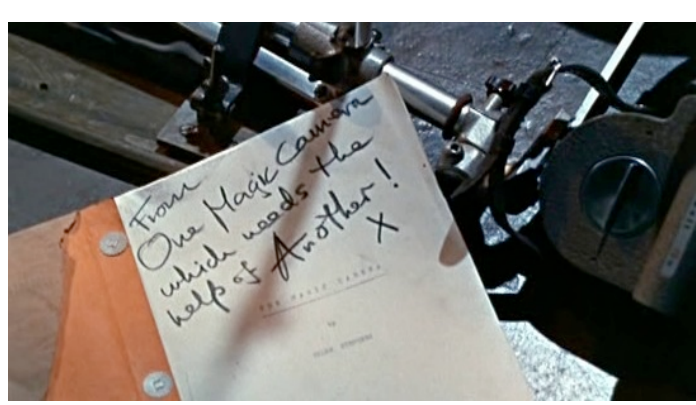

De esta manera, con la excusa narrativa de que Ray X y su cámara de vídeo capture y registre todo aquello que necesita Ernesto "padre” como prueba de la infidelidad de Mateo Blanco y su querida Lena, Almodóvar inserta la imagen electrónica en la propia textura del film, de tal manera que, tal y como explica el mismo cineasta:

"Martel "padre" ve el material grabado en estado crudo. Proyecta las cintas de vídeo recién salidas de la cámara de su hijo, supervisadas solo por la autómata lectora de labios [...] En ese momento el marking of, producido por Martel con intenciones perversas, se vuelve contra él. Lena le abandona por partida doble, en la pantalla y desde la puerta del salón, a sus espaldas" (Almodóvar, 2009: 10).

Ray X toma el testigo de Mark Lewis y convierte la imagen en prueba irrefutable de una realidad, que como huella de un referente arrastrado, Ernesto “padre” no duda en aceptar como verdad. Es así, como el joven, al igual que los rayos $\mathrm{X}$-no causales igualmente- realizados a Lena tras ser empujada por Ernesto escalera abajo después de que ella lo abandone, en lo que se supone un examen médico no invasivo, a través de los cuales se muestra lo más oculto del cuerpo de la protagonista, va más allá de la figura del voyeur para penetrar hasta lo imperceptible, exponiendo la relación de la joven y Mateo Blanco, con imágenes que brotan del interior mismo de ambos y que se resumen en el primer beso que queda congelado y que prefigura el último de la pareja, aquel que se traduce en la poderosa imagen surgida de las esencias de Rossellini y Antonioni [ver foto 7]. 
Ciertamente, Ray X, en su documental como él lo llama sobre Mateo Blanco, reescribe la historia que comenzara Mark Lewis y la convierte la imagen reveladora del terror en la imagen reveladora del amor. Almodóvar sitúa en un momento determinado del film, ese en el que Harry Caine visita a Ernesto "hijo" en su estudio, en la posición que ocupa la madre ciega de Helen en El fotógrafo del pánico, y para que no haya dudas al respecto, el mismo protagonista le dice al joven documentalista: "Me recuerdas a Peeping Tom", mientras apunta con su bastón, en este caso no lacerante, hacia la cara de Ray X; a lo que este responde: "Si, pero yo nunca quise matarte". Sin embargo, la imagen subjetiva a la cual el espectador de la película de Powell

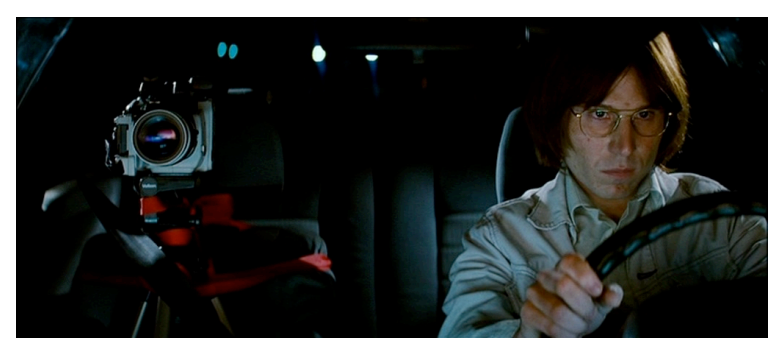
tiene acceso, se transforma en el film almodovariano en una mirada enunciativa, de tal manera que, al igual que sucede en Blow up, la cámara se hace autónoma en un gesto protagonizado por el propio Ernesto, quien la antropomorfiza y la convierte en el copiloto que registra todo lo acaecido la noche del accidente [foto 12] para, posteriormente, digitalizarla, proporcionando a Mateo el placer de recrearse en ella con un gesto, que aunque visualmente remite al protagonizado por Mark Lewis y la madre de Helen cuando acarician desesperadamente las imágenes del terror -que no dejan de sucederse en la pantalla y que incluso invaden los cuerpos de ambos-, se encuentra en las antípodas de lo planteado por Powell. Por eso, Mateo Blanco se recrea en dicho placer y las posibilidades que le ofrece la imagen electrónico-digital y solicita a su hijo que le pase esta imagen cuadro a cuadro, "para que dure más", por mucho que lo verdadero en la imagen digital, como dice Quintana, sean las sensaciones ópticas que genera la superficie de dicha imagen (Quintana, 2011: 78), inmortalizada en origen por la ligereza de la cámara electrónica que ha permitido capturar el instante revelador que lo resume todo en este film, aceptando la exploración de una nueva temporalidad expresada mediante el propio gesto de Mateo. 


\section{3. Finalmente ¿Chicas y maletas?}

Solo nos queda hablar por último en esta reflexión propuesta por Almodóvar sobre la imagen y su construcción, de esa parte de film gracias a la cual la cámara almodovariana penetra en los intersticios del medio cinematográfico con la intención de recrearse en el acto creativo: el protagonista de Los abrazos rotos, en su roll como cineasta, construye otro film que finalmente se inserta en la ficción: Chicas y maletas, un film que tampoco se agota en él mismo como veremos. En torno al universo ficcional creado por Mateo Blanco, se produce, como ya hemos explicado, un discurso autorreflexivo y autorreferencial que traspasa los límites del propio relato almodovariano, y al mismo tiempo, desborda los márgenes de los distintos textos que el film moviliza para resquebrajarlos.

Así, Chicas y maletas funciona en Los abrazos rotos como el eslabón que une Mujeres al borde de un ataque de nervios, película en la que encuentra su origen, y La concejala antropófaga, una pequeña joya que surge, como decimos, de la película creada por Mateo Blanco en la ficción. Sin embargo, no es la intención del artista autohomenajerse "espero -dice- que nadie lo interprete así” (Almodóvar, 2009: 13), por eso, quizá haya que referirse a él como un palimpsesto en el que, aunque se conservan huellas de una escritura anterior, el diseño de producción ha hecho posible una nueva escritura que reinterpreta a la anterior.

En cuanto al resultado de la obra generada a partir de la elaboración de Chicas y maletas: La concejala antropófaga, podríamos encontrar el referente más próximo, en relación al gesto autorreferencial que representa, en Tráiler para amantes que, aunque sin mostrar ni una sola imagen de su otro film, iQué he hecho YO para merecer esto!, "hace una extraordinaria y gratuita publicidad del film, al mismo tiempo que inventa otra historia basada en él” (Holguín, 2006: 122). De esta forma, los cortometrajes que surgen en el interior mismo de Los abrazos rotos se convierten en palimpsestos, como decíamos más arriba, de las obras que reescriben y que les preceden. 
Sin embargo, más allá de esta autodigestión de textos que se haya explícita en el film, nos interesa destacar cómo Almodovar utiliza la realización de Chicas y maletas dentro del universo ficcional, para seguir analizando y profundizando sobre el acto creativo en relación al proceso cinematográfico. $\mathrm{Y}$ es que, el fundido a negro que se produce después de que la cámara se recree en la imagen nuclear del film, trae consigo unas imágenes que no hacen sino constatar la importancia de las nuevas tecnologías en el desarrollo de la creación. Por eso, Almodóvar dota de protagonismo en esta última parte del film, al instrumento sin el cual la fase de montaje, en la actualidad, no sería posible: el ordenador. En este sentido hemos de subrayar que tanto las imágenes analógicas como la digitales que han sido filmadas previamente pasan al disco duro de estos aparatos, antes de ser montadas y sonorizadas, convirtiéndose este en "determinante en todos los procesos creativos del cine" (Quintana, 2011: 71), procesos a los que el cineasta manchego presta singular atención puesto que muestra detalladamente el momento en el que el puntero del ratón movido por Mateo [foto 13], va seleccionando en la computadora aquellos fragmentos de imagen y sonido que una vez afinados se muestran como definitivos, de tal forma que se produce un doble reencuadre en el que la pantalla cinematográfica alberga en su interior esa otra, la del ordenador que reproduce la secuencia de Chicas y maletas [foto 14].
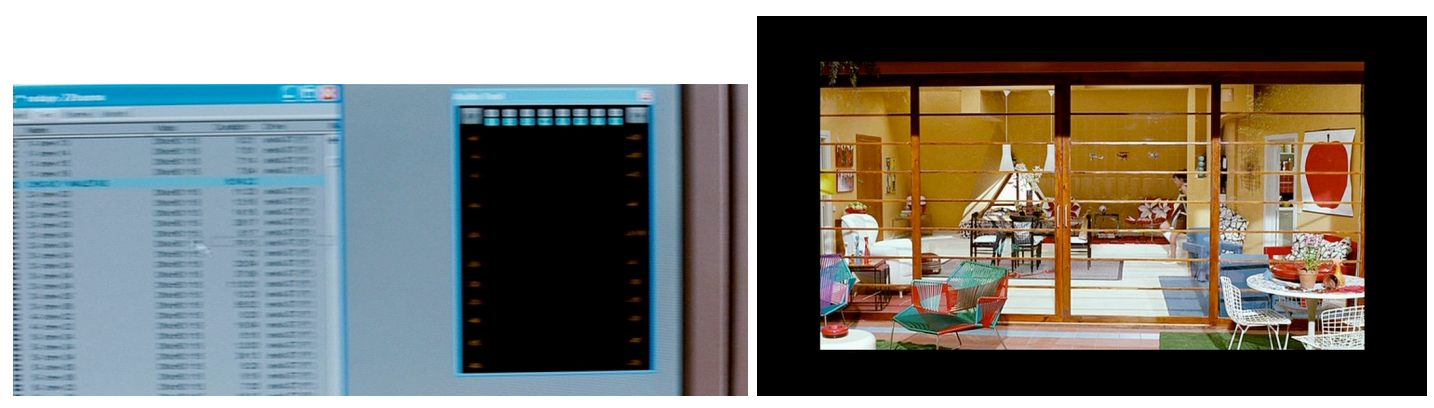

Ciertamente, el propio Almodóvar se refiere a cómo: "En la trama de Los abrazos rotos, aparece dramatizada la importancia del montaje, su relación directa con el autor y la fragilidad de la obra si alguien se interpone en el montaje y él” (Almodóvar, 2009: 8). Pero más allá del hecho narrativo, el cineasta manchego hace hincapié en la importancia de las nuevas tecnologías 
que han barrido -según él- todos los materiales magnéticos y fotográficos de las salas de montaje (Almodóvar, 2009: 8). De esta manera, el homenaje a las mismas por arte del autor, pone el broche final a este film almodovariano en el que el hecho fílmico se impone sobre cualquier otro elemento. Tanto es así que el film manifiesta como imperativo el deber de todo cineasta de acabar sus películas, "aunque sea a ciegas", tal y como concluye Mateo Blanco, alter ego de Almodóvar en este universo ficcional.

\section{Referencias bibliográficas}

ALLINSON, Mark (2003). Un laberinto español. Las películas de Pedro Almodóvar, Madrid: Ocho y Medio.

ALMODÓVAR, Pedro (2009). Los abrazos rotos, Madrid: El deseo, URL: http://www.losabrazosrotos.com/, 3-5-2012.

ARONICA, Daniela (2005). "Intertextualidad y autorreferencialidad: Almodóvar y el cine español”. En Almodóvar: el cine como pasión, pp. 57-80.

BERGMAN, Igman (1992). Imágenes, Barcelona: Tusquets.

COMPANY, Juan Miguel (1981). El autor y su obra. Bergman, Barcelona: Barcanova.

FONTCUBERTA, Joan (2010). Blow-up Blow-up. Cáceres: Editorial Periférica.

GÁLLEGO, Julián (1987). El cuadro dentro del cuadro. Madrid: Cátedra.

GENETTE, Gérard (1989). Palimpsestos, Madrid: Taurus.

HEREDERO, Carlos (2009). "Entrevista Pedro Almodóvar. El cielo protector", Cahier du cinema (España), No 21, Madrid, Ediciones Caimán, pp. 7-12.

HOLGUín, Antonio (2006). Pedro Almodóvar, Madrid: Cátedra.

LACAN, Jacques (1984). Seminario III: Las Psicosis (1955-1956). Buenos Aires, Argentina: Paidós.

MARKU, Sas (2001). La poética de Pedro Almodóvar. Barcelona: Littera.

MÉJEAN, Jean-Max (2007). Pedro Almodóvar. Barcelona: Ediciones Robinbook.

PERALES, Francisco (2008). "Pedro Almodóvar: heredero del cine clásico". En Revista Zer, No 24, Vol. 13. Universidad del País Vasco. pp. 281301.

PÉREZ BOWIE, José Antonio (2006). "El cine en, desde y sobre el cine: 
metaficción, reflexividad e intertextualidad en la pantalla”. En Revista Anthropos, $\mathrm{n}^{\circ}$ 208. Barcelona: Anthropos Editorial, pp. 122- 137.

POYATO, Pedro (2006). Introducción a la teoría y el análisis de la imagen fo-cinema-tográfica. Granada: Grupo Editorial Universitario.

POYATO, Pedro (2007). Todo sobre mi madre. Valencia: Ediciones Octaedro.

QUINTANA, Ángel (2003). Fábulas de los visible. El cine como creador de realidades. Barcelona: Acantilado.

QUINTANA, Ángel (2009). “A ciegas”. En Cahiers du cinema (España), No 22, Madrid, Ediciones Caimán, pp. 28-29.

QUINTANA, Ángel (2011). Después del cine. Imagen y realidad en la era digital. Barcelona: Acantilado.

STRAUSS, Frédéric (1995). Pedro Almodóvar. Un cine visceral. Madrid: El País Aguilar.

VIDAL, Nuria (1998). El cine de Pedro Almodóvar. Barcelona: Ediciones Destino.

VILLANUEVA, Darío (2008). “Autobiografía (Camilo José Cela) y Biografía (Ricardo Franco) de Pascual Duarte". En El realismo y sus formas en el cine rural español, P. Poyato (ed.), Córdoba: Ayuntamiento de Dos Torres y Diputación de Córdoba, pp. 51-84. 